\title{
Statins utilization and price variations-comparison between Ukraine and Bulgaria.
}

\author{
Zornitsa Mitkova $^{1 *}$, Manoela Manova ${ }^{1}$, Alexandra Savova ${ }^{1}$, Anna Peneva ${ }^{1}$, Javor Mitkov ${ }^{2}$, Oksana \\ Tkachova $^{3}$, Larysa Iakovlieva ${ }^{3}$, Valentina Petkova ${ }^{1}$, Guenka Petrova ${ }^{1}$ \\ ${ }^{1}$ Department of Social Pharmacy, Medical University, Sofia, Bulgaria \\ ${ }^{2}$ Department of Pharmaceutical Chemistry, Medical University, Sofia, Bulgaria \\ ${ }^{3}$ Department of Pharmacoeconomics, National University of Pharmacy, Kharkiv, Ukraine
}

\begin{abstract}
Introduction: High prevalence rate of CVD and high rate of CVD deaths attributed to high cholesterol leads to increased statins utilization. The aim of this study is to analyse the difference in prices between generic and innovator and utilization of INNs of statins available in Bulgaria and Ukraine.

Materials and methods: The study is retrospective and observational analysis of changes in prices. On total, 7 INN and 18 dosage forms are included in the study. Utilization of statins has been measured in DDD/1000 inh/d.

Results: The results reveal considerable price differences in the prevailing part of the observed dosage forms between 2013 and 2016 and higher price variations. Two of the lowest and three of the highest prices have not been changed in Bulgaria. For the same period in Ukraine ten lowest and five highest prices have decreased, while one lowest and six highest have increased. Statins utilization is much higher in Bulgaria than that in Ukraine.

Conclusions: Prices of statins tend to decrease in Bulgaria more than in Ukraine. In both countries there is a slight tendency of reduced utilization, whereas the consumption of statins in Bulgaria is much higher than that in Ukraine. The study confirms that medicine utilization depends on prices and the health policy in the countries.
\end{abstract}

Keywords: Statins, Price, Utilization, DDD/1000 inh/d, Bulgaria, Ukraine.

Accepted on September 25, 2018

\section{Introduction}

Statins are widely used nowadays for treatment of hypercholesterolemia. There is much evidence that statin therapy improves cardiac function, symptoms associated with idiopathic dilated cardiomyopathy, blood lipid level, therapy satisfactions [1,2] and reduces all-cause mortality and morbidity [3]. Five years primary prevention treatment of middle-aged men which is economically effective, leads to cost saving and increases quality adjusted life years [4].

Among both European Union (EU) and non-EU member states, cardiovascular disease (CVD) prevalence tended to be relatively high in Eastern and Central European countries. Age-standardized prevalence rate of CVD per 100,000 in Bulgaria (BG) decreases from 9,359 in 1990 to 9,068 in 2015. In Ukraine (UA) an increase is found out from 8,708 in 1990 to 8,801 in 2015 . The percentage of raised blood cholesterol is $49.9 \%$ in Bulgaria and $44.4 \%$ in Ukraine, showing from moderate to high rate in Europe (the lowest rate is $26.8 \%$ in Uzbekistan, and the highest one is $69.8 \%$ in Iceland) [5].
Utilization of lipid lowering agents varied among countries-in 2003 the highest is in Ireland and Norway, and lowest in Italy. It has increased in all observed countries e.g. by $274 \%$ in Ireland and by 56\% in France between 2000 and 2003 [6].

Despite the high prevalence of CV morbidity and mortality a little is known about the statins utilization and their prices in BG and UA. The data about statins utilization and prices are necessary from policy point of view to estimate their affordability to the population, and to minimize the risk of underutilization. High prevalence rate of CVD deaths attributed to high cholesterol, the increased prescribing and utilization, and their link to price levels and price variations, has prompted our interest in this study.

\section{Materials and Methods}

The study is retrospective, observational analysis of changes in prices. On total, 7 international non-proprietary names (INNs) and 18 dosage forms of statins (Anatomic therapeutic chemical (ATC) code C10AA) are observed during 2013-2016. 


\section{Price variations analysis}

Retail prices of all authorized statins in Bulgaria were collected from the official registry of the National council of pricing and reimbursement [7] and from market research system "Pharm standard" of the company "Morion" in Ukraine [8].

The lowest and the highest priced statins were compared by calculating the ratio between them, as follows:

Generics to originators price ratio=The lowest generics price/ Price of originator or the highest generics price

All prices are converted in $€$ at the exchange rate of $1 \mathrm{BGN}=$ $€ 0.51$ in Bulgaria [9]. In Ukraine $1 €$ equals $10.92 \mathrm{UAH}$ in $2013,1 €$ equals $17.12 \mathrm{UAH}$ in $2014,1 €$ equals $24.36 \mathrm{UAH}$ in 2015 and $1 €$ equals 28.28 UAH in 2016 according to Ministry of Finance in Ukraine [10].

\section{Utilization of statins}

The statins utilization was calculated for every year using the World Health Organization (WHO) formula [11]:

$\mathrm{DDD} / 1000 \mathrm{inh} / \mathrm{d}=(($ Sales data in $\mathrm{mg} / \mathrm{DDD}$ in $\mathrm{mg}) /(\mathrm{N}$ in habitants $\times 365)) \times 1000$

Sales data were provided from Bulgarian Drug Agency (BDA), number of inhabitants is published in National Statistical Institute database [12] in Bulgaria $(n=7245677$ in 2013, 7202198 in 2014; 7153784 in 2015). In Ukraine number of inhabitants is published from State Statistics Service of Ukraine ( $\mathrm{n}=45553000$ in 2013; 45426200 in 2014; 42928900 in 2015) [13].

\section{Results}

\section{Price variations analysis in $B G$ and $U A$}

Our study founds a large variation of the statins prices during 2013-2016. As a whole, prices vary more in Ukraine, while they are steadier in Bulgaria (Table 1).

Table 1. Number of observed products and those with price changes between 2013-2016.

\begin{tabular}{|c|c|c|c|c|c|c|}
\hline & \multicolumn{2}{|c|}{$2013 / 2014$} & \multicolumn{2}{|c|}{$2014 / 2015$} & \multicolumn{2}{|c|}{$2015 / 2016$} \\
\hline & BG & UA & BG & UA & BG & UA \\
\hline $\begin{array}{l}\text { Total number of compared dosage } \\
\text { forms }\end{array}$ & 28 & 29 & 28 & 31 & 28 & 30 \\
\hline \multicolumn{7}{|l|}{ Number of products, whose price: } \\
\hline Decreased & 13 & 23 & 6 & 19 & 9 & 23 \\
\hline Increased & 3 & 6 & 1 & 12 & 2 & 7 \\
\hline Remained unchanged & 12 & - & 21 & - & 17 & - \\
\hline
\end{tabular}

The price ratio was calculated for 3 INNs of statins (simvastatin, atorvastatin, and rosuvastatin), as they are available on the market under more than one trademark (Table 2). The medicines with the same trade name were excluded. Generic to originator price ratio in $\mathrm{BG}$ for all INNs varies between 0.09-0.77, while in Ukraine it is from 0.06 to 0.74 over the observed period of time (Table 2).

Table 2. Generics to originators ratio during 2013-2016.

\begin{tabular}{|c|c|c|c|c|c|c|c|c|c|}
\hline \multirow[t]{2}{*}{ INN } & \multirow[t]{2}{*}{ Medicines strength } & BG & BG & BG & BG & UA & UA & UA & UA \\
\hline & & 2013 & 2014 & 2015 & 2016 & 2013 & 2014 & 2015 & 2016 \\
\hline Simvastatin & 10 & 0.26 & 0.26 & 0.26 & 0.26 & 0.46 & 0.25 & 0.18 & 0.22 \\
\hline Simvastatin & 20 & 0.12 & 0.12 & 0.12 & 0.12 & 0.37 & 0.37 & 0.27 & 0.33 \\
\hline Simvastatin & 40 & 0.17 & 0.11 & 0.11 & 0.11 & 0.32 & 0.18 & 0.27 & 0.18 \\
\hline Atorvastatin & 10 & 0.12 & 0.15 & 0.17 & 0.18 & 0.12 & 0.19 & 0.1 & 0.09 \\
\hline Atorvastatin & 20 & 0.09 & 0.14 & 0.14 & 0.14 & 0.13 & 0.13 & 0.07 & 0.08 \\
\hline Atorvastatin & 40 & 0.18 & 0.3 & 0.13 & 0.13 & 0.26 & 0.21 & 0.16 & 0.15 \\
\hline Atorvastatin & 80 & 0.37 & 0.65 & 0.65 & 0.24 & 0.74 & 0.4 & 0.25 & 0.18 \\
\hline Rosuvastatin & 5 & 0.12 & 0.09 & 0.09 & 0.09 & 0.6 & 0.29 & 0.28 & 0.09 \\
\hline Rosuvastatin & 10 & 0.18 & 0.18 & 0.19 & 0.13 & 0.23 & 0.06 & 0.07 & 0.06 \\
\hline Rosuvastatin & 20 & 0.22 & 0.17 & 0.17 & 0.18 & 0.28 & 0.09 & 0.08 & 0.09 \\
\hline Rosuvastatin & 40 & 0.42 & 0.77 & - & - & 0.43 & 0.2 & 0.21 & 0.24 \\
\hline
\end{tabular}

*the lowest and highest ratios are bolded

The results of applied Wilcoxon Signed Ranks Test show statistically significant differences between rosuvastatin prices in Bulgaria ( $p=0.028$ ) compared in 2013 and 2016. There were no significant differences between prices of the other INNs. 


\section{Utilization of statins}

Utilization of statins in DDD/1000/inh/d is presented on Table 3.

Table 3. Statins utilization in DDD/1000 inh/day in BG and UA during 2013-2015.

\begin{tabular}{llllllll}
\hline INN & $\begin{array}{l}\text { DDD } \\
(\mathbf{m g})\end{array}$ & BG & \multicolumn{7}{c}{ UA } \\
\cline { 3 - 8 } & & $\mathbf{2 0 1 3}$ & $\mathbf{2 0 1 4}$ & $\mathbf{2 0 1 5}$ & $\mathbf{2 0 1 3}$ & $\mathbf{2 0 1 4}$ & $\mathbf{2 0 1 5}$ \\
\hline Simvastatin & 30 & 6.83 & 6 & 4.03 & 0.38 & 0.31 & 0.16 \\
\hline Fluvastatin & 60 & 0.34 & 0.337 & 0.17 & 0.0001 & 0.0000 & 0.0000 \\
\hline Lovastatin & 45 & 0.12 & 0.338 & 0.18 & 0.0100 & 0.0080 & 0.0080 \\
\hline Atorvastatin & 20 & 8.31 & 9 & 5.68 & 2.6900 & 2.6300 & 2.3400 \\
\hline Rosuvastatin & 10 & 9.11 & 11 & 10.41 & 1.3100 & 1.7700 & 2.0200 \\
\hline
\end{tabular}

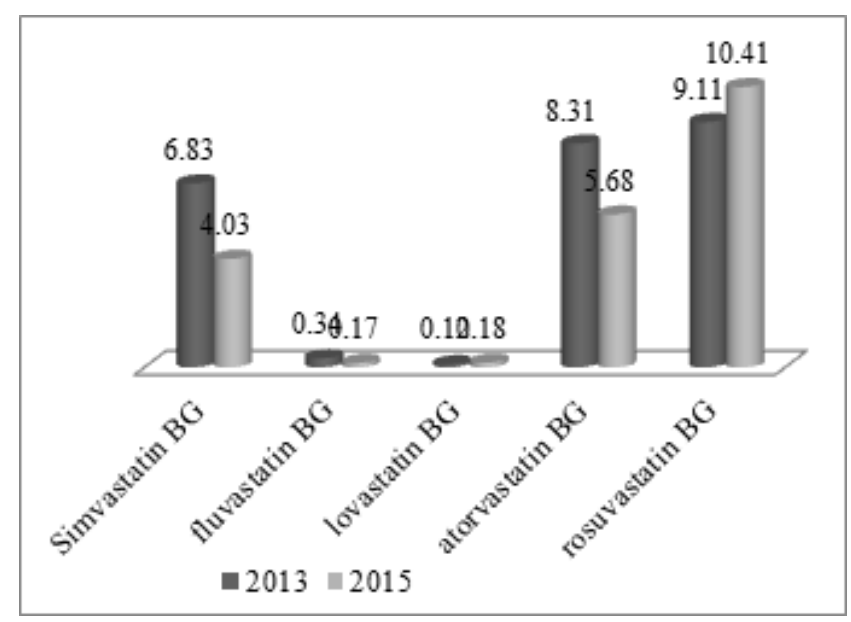

Figure 1. Utilization of statins in 2013 and 2015 in Bulgaria.

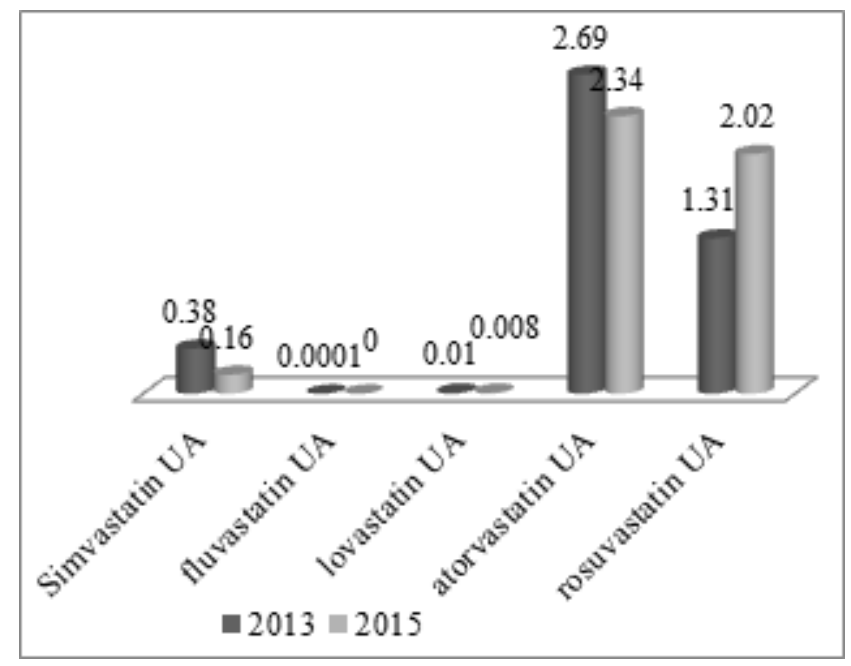

Figure 2. Utilization of statins in 2013 and 2015 in Ukraine.

The utilization is much higher in BG than UA-about 3000 times for fluvastatin in 2013 and 25.2 times for simvastatin in 2015 (Figures 1 and 2). The highest utilization was estimated for rosuvastatin in Bulgaria and atorvastatin in Ukraine. Those INNs show notable price changes for this period of time.

\section{Discussion}

Development of the pharmaceutical market in Bulgaria has led to an increased number of generics in the last few years. A previous study confirms that a large number of generics were approved, the prices decreased significantly, and simultaneously changed medicines utilization. This process is more evident in the developing groups and new approved INNs [14] where generic and therapeutic competition influence the market environment, they could even realize budget savings [15]. A previous study showed that eight new generic atorvastatin and ten new rosuvastatin were included for reimbursement during 2009-2013, which led to price decrease and utilization growth. This study confirms that the development of generic policy, price stability, and low rate of patient co-payment are required in order to prevent patients' non-adherence and improve health outcomes.

Similar study in Ukraine estimated an increased number of a statin group by $30.4 \%$ from 2012 to 2015 . The highest growth of rosuvastatin $(129 \%)$ was recorded. The prices for domestic statins increased on average by $42.1 \%$. The average prices also increased on the market especially for imported products [16].

One of the reasons for the permanent prices decrease in Bulgaria could be the strict price regulation. The National Council on Pricing and Reimbursement (NCPRMP) [17] approves medicine prices based on the lowest price among the 17 reference countries. The manufacturer price of the generic product should not exceed $70 \%$ of the price of the originator.

The register for medicines subject to reimbursement has been created in July 2017 in Ukraine. Only simvastatin (5 trade names) of $90 \%$ reimbursement level was included in the register [18].

The generic to originator ratio expresses the price contrast and the results of the introduced generic policy in a country. The difference between the most and least expensive dosage forms, established on a market is probably the result of the manufacturer's policy and the health economic environment. The countries (e.g. Denmark, Sweden) which have strict generic policies, tend to have a higher difference between originator and generic prices [19].

A higher price difference between generic and originator could affect medicines utilization and resulting in increased morbidity and cardiovascular mortality [16].

The study including nine European countries shows the highest rate of increase of statins utilization in Ireland-from 26.54 to 99.29 DDD/1000 inh/d during 1997-2003 [6]. The utilization of statins in our study is far below those values, especially in Ukraine.

The utilization of statins in $\mathrm{CZ}$ has risen from 2 to $96 \mathrm{DDD} /$ $1000 \mathrm{inh} / \mathrm{d}$ between 1997 and 2013 [20], while utilization in Serbia is 0.06 in 2003 and $0.30 \mathrm{DDD} / 1000 \mathrm{inh} / \mathrm{d}$ in 2004 [21]. The study reveals that the utilization of statins in Bulgaria is close to that in $\mathrm{CZ}$, as well as in Ukraine it is similar to that of Serbia. 
This is the first comparative study of both price changes and utilization of statins among Bulgaria and Ukraine, the countries of the highest CVD morbidity and mortality in Europe. It tested the relationship between prices and utilization and confirms that the price stability affects medicines utilization, affordability and compliance to therapy.

\section{Conclusion}

Prices of statins tend to decrease in Bulgaria more than in Ukraine. In both countries there is a slight tendency of reduced utilization, whereas the consumption of statins in Bulgaria is much higher than that in Ukraine. The study confirms that medicine utilization depends on prices and the health policy in the countries. Some factors such as price variability, differences between the lowest and the highest priced medicines, and the rate of co-payment could affect statins consumption and prescribing habits.

\section{References}

1. Node K, Fujita M, Kitakaze M, Hori M, Liao JK. Shortterm statin therapy improves cardiac function and symptoms in patients with idiopathic dilated cardiomyopathy. Circulation 2003; 108: 839-843.

2. Chen Q, Chen L, Guo X, Zhang J. Clinical efficacy of statins in the prevention and treatment of coronary heart disease. Biomed Res 2018; 29: 309-312.

3. Sola S, Mir MQ, Rajagopalan S, Helmy T, Tandon N, Khan BV. Statin therapy is associatedwith improved cardiovascular outcomes and levels of inflammatory markers in patients with heart failure. J Card Fail 2005; 11: 607-612.

4. McConnachie A, Walker A, Robertson M, Marchbank L, Peacock J, Packard CJ, Cobbe SM, Ford I. Long-term impact on healthcare resource utilization of statin treatment, and its cost effectiveness in the primary prevention of cardiovascular disease: a record linkage study. Eur Heart J 2014; 35: 290-298.

5. Wilkins E, Wilson L, Wickramasinghe $\mathrm{K}$, Bhatnagar $\mathrm{P}$, Leal J, Luengo-Fernandez R, Burns R, Rayner M, Townsend N. European Cardiovascular Disease Statistics 2017. European Heart Network, Brussels 2017.

6. Walley T, Folino-Gallo P, Stephens P, Van Ganse E. Trends in prescribing and utilization of statins and other lipid lowering drugs across Europe 1997-2003. Br J Clin Pharmacol 2005; 60: 543-551.

7. The National Council on Prices and Reimbursement of Medicinal Products in Bulgaria. Annex 1 to PDL.

8. Software Complex Pharmacy Company Morion.

9. Bulgarian national bank http: //www.bnb.bg/

10. Ministry of Finance of Ukraine. Available from: https: // charts.finance.ua/ru/currency/cash/-/0/eur
11. WHO Collaborating Centre for Drug Statistics Methodology. Guidelines for ATC classification and DDD assignment 2018. Oslo, Norway 2017.

12. National Statistical Institute of Bulgaria. Population by districts, place of residence and gender. Available at http:// ghdx.healthdata.org/organizations/national-statisticalinstitute-bulgaria

13. State Statistics Service of Ukraine. Available from: http: // www.ukrstat.gov.ua

14. Mitkova Z, Manova M., Petrova G. Relationship between generic competition and generic utilization of cardiovascular medicines monoproducts in Bulgaria. Pharmacia 2016; 63: 3-14

15. Dimitrova M, Doneva M, Petrova G. An analysis of budgetary impact following treatment of essential hypertension with novel AT1 receptor antagonist. Cardiovasc Dis 2013; 44: 23-28.

16. Bezditko N, Iakovlieva L, Mishchenko O, Chynush I, Toryanik E. Pharmacoepidemiological analysis: dynamics of availability of statins in Ukraine. Clin Pharm 2016; 20: 6-10.

17. Ordinance on the terms, rules and procedure for regulation and registration of prices for medicinal products 2013.

18. Reference pricing and reimbursement of medicines to be introduced in 2017 Healthcare Ministry.

19. Vogler S. How large are the differences between originator and generic prices? Analysis of five molecules in 16 European countries. Farmeconomia. Health Econom Therap Pathways 2012; 13: 29-41.

20. Fuksa L, Vocelka M, Vytrisalova M. The impact of changes in national prescribing conditions for statins on their public expenditure and utilization in the Czech Republic 1997-2013. Health Policy 2015; 119: 1255-1264.

21. Velickovic-Radovanovic R, Jankovic S, Avramovic M , Svetislav Kostic. The use of cardiovascular drugs in Niš region of Serbia. Facta Universitatis Series Med Biol 2006; 13: 94-97.

\section{*Correspondence to}

Zornitsa Mitkova

Department of Social Pharmacy

Medical University

Sofia

Bulgaria 